MRS. CAROLINE TEULIER (Orcid ID : 0000-0003-4400-783X)

Article type : Paper (under 8000 words)

\title{
Newborn crawling and rooting in response to maternal breast odor
}

\section{Charlotte Hym ${ }^{\text {a*}}$, Vincent Forma a *, David I. Anderson ${ }^{b}$, Joelle Provasi ${ }^{\text {c }}$, Lionel Granjon a, Viviane Huet a, Emilie Carpe $^{\text {a }}$, Caroline Teulier ${ }^{\text {d,e }}$, Karine Durand ${ }^{\text {f }}$, Benoist Schaal ${ }^{\text {f, }}$ Marianne Barbu-Roth a}

a Integrative Neuroscience and Cognition Center, Université de Paris - CNRS

${ }^{\mathrm{b}}$ Marian Wright Edelman Institute, San Francisco State University

${ }^{c}$ Laboratoire CHArt, Ecole Pratique des Hautes Etudes, Paris, France

${ }^{\mathrm{d}}$ Université Paris-Saclay CIAMS, 91405, Orsay, France

e Université d'Orléans, CIAMS, 45067, Orléans, France

${ }_{\mathrm{f}}$ Developmental Ethology and Cognitive Psychology Group, Center for Taste, Smell and Feeding Science, UMR 6265 CNRS-Université de Bourgogne-Franche-Comté, Dijon, France

* Charlotte Hym \& Vincent Forma contributed equally to the present work

Correspondence concerning this manuscript should be addressed to: Marianne Barbu-Roth Integrative Neuroscience and Cognition Center - UMR 8002 CNRS - Université de Paris, 45 Rue des Saints Pères, 75006 Paris France; Phone: (33) 14286 4323; Fax: (33) 14286 3322; Email: marianne.barburoth@parisdescartes.fr

This article has been accepted for publication and undergone full peer review but has not been through the copyediting, typesetting, pagination and proofreading process, which may lead to differences between this version and the Version of Record. Please cite this article as doi: 10.1111/DESC.13061

This article is protected by copyright. All rights reserved 


\section{Acknowledgments}

This work was supported by grants from the Agence Nationale de la Recherche (ANR-11-BSH2007 01), Région Ile-de-France, and the Fondation de France(2014 00052248). We would like to thank all infants and parents who participated in the study and the Ecole Supérieure d'Ostéopathie for their support to Emilie Carpe.

\section{Research Highlights}

- Human newborns can not only recognize maternal breast/milk odor but can modify their crawling efficiency in response to this odor.

- The mechanism underlying this increased locomotor efficiency is not due to an arousal increase as the maternal odor decreases the number of steps.

- Our data suggest that newborn crawling is not a simple spinal reflex; it can be controlled at a supra spinal level via brain processed odors.

- The findings have implications for the design of interventions to facilitate locomotor development in infants at risk for developmental delay. 


\begin{abstract}
A growing literature shows that perception and action are already tightly coupled in the newborn. The current study aimed to examine the nature of the coupling between olfactory stimuli from the mother and the newborn's crawling and rooting (exploratory movements of the head). To examine the coupling, the crawling and rooting behavior of 28 2-day-old newborns were studied while they were supported prone on a mobility device shaped like a mini skateboard, the Crawliskate ${ }^{\circ}$, their head positioned directly on top of a pad infused with either their mother's breast odor (Maternal) or the odor of water (Control). Video and 3D kinematic analyses of the number and types of limb movements and quantification of displacement across the surface revealed that newborns are significantly more efficient crawlers when they smell the maternal odor, moving greater distances although performing fewer locomotor movements. In addition, the newborns made significantly more head rooting movements in the presence of the maternal odor. These findings suggest that the circuitry underlying quadrupedal locomotion and exploratory movements of the head is already adaptable to olfactory information via higher brain processing. Moreover, the coupling between olfaction and the two action systems, locomotion and rooting, is already differentiated.

As crawling enables the newborn to move toward the mother's breast immediately after birth and facilitates mother-infant interaction, the results of this study highlight the potential value of using maternal odors to stimulate mobility in infants at risk of motor delay and/or deprived of this odor when born prematurely.
\end{abstract}

Keywords: newborn, locomotion, perception-action coupling, rooting, olfaction

\title{
Newborn crawling and rooting in response to maternal breast odor
}

\section{Perception-action coupling in the newborn}

Until the latter part of the $20^{\text {th }}$ century, researchers and clinicians assumed that human newborns had limited control over their behavior. They considered the newborn incapable of prospectively adapting its movements in anticipation of a stimulus or voluntarily modifying its movements in response to variations in a stimulus because its behavior was governed by a repertoire of primitive reflexes, the circuitry for which resided in the spinal cord and brainstem. 
Those assumptions were challenged by a series of landmark studies in the 1980s and 1990s. For example, studies showed that newborns would initiate voluntary reaching movements toward an object when provided with appropriate postural support (Grenier, 1983; von Hofsten, 1982) and that they could modulate their hand activity on an object in response to variations in its texture (Molina \& Jouen, 1998). Other studies showed that finger movements differed when newborns viewed a moving object versus their mother, with the movements differing again when neither the object or the mother were present (Rönnqvist \& von Hofsten, 1994). A very well-cited study showed that newborns could purposely control their arm movements to keep their hand in their field of view (Van der Meer, Van der Weel \& Lee, 1995) whereas a series of studies on sucking showed they could adapt the temporal or rhythmic pattern of their sucking (Craig \& Lee, 1999) to elicit the contingent sound of their mother's voice (De Casper and Fifer, 1980; Moon, Cooper \& Fifer, 1993) or to stay in rhythm with an auditory beat (Bobin-Bègue et al., 2006).

Despite this considerable and growing evidence of neonatal perception-action competency, some behaviors are still regarded as inflexible primitive reflexes, unresponsive to variations in sensory input and immune from higher-brain control. This is the case for newborn crawling, a behavior often described as a spinally-mediated reflex that helps the newborn move toward the mother's breast at birth. However, recent research by Forma and collaborators suggests that newborns modify their crawling patterns in response to visual stimuli that are processed by higher brain centers (2018). Would crawling respond to other stimuli processed by higher brain centers? Olfaction has been shown to govern motivated responses in term-born and prematurely-born human neonates (cf. Schaal et al., 2004; Schaal et al. 2020, for reviews). Here we investigate if (and how) neonatal crawling adapts to olfactory stimuli - information known to be processed at the cortical level (e.g., Bartocci et al., 2000; Ayoama et al., 2010; Adam-Darque et al., 2017; Frie et al., 2017). As the function of newborn crawling is presumably to aid breast/nipple finding and feeding, we also investigated newborn rooting, sweeping movements of the head that also help the newborn locate the feeding source. We were curious to know how the two behaviors collaborated and whether their responsiveness would be differentiated in the presence of the same olfactory information.

\section{Maternal odor and human newborn rooting and locomotion}

Rooting movements: Small bilateral head displacements related to the search for the nipple are well described in human infants (Prechtl, 1958; Takahashi et al., 2015; Glodowski, Thompson, $\&$ Martel, 2019). However, quantitative measurements of such rooting behaviors have only rarely 
been reported (e.g., Doucet et al., 2009). Rooting is a complex behavioral pattern composed of bilateral head movements accompanied by head orientation and lifting (if the infant is lying prone), and asymmetrical oral searching that are displayed when an infant's perioral skin contacts a surface or is touched by another person (Rochat \& Hespos,1997). Prechtl (1958) described it as a "pendulous orientating response". The rooting sequence is "the seeking component of suckling" (Papousek, 1961). It helps newborns to locate and orally seize a nipple and its full display depends on their state of arousal and/or hunger (e.g., Gentry \& Aldrich, 1948; Prechtl, 1958; Wolff, 1959; Takahashi et al., 2015; Glodowski, Thompson, \& Martel, 2019). Rooting is less studied in human newborns compared to sucking or head orientation movements because it is difficult to analyze (e.g., Widström \& Thingström-Paulsson, 1993). Importantly, however, although the most studied sensory triggers for rooting are tactile or thermotactile, recent evidence suggests that olfactory stimuli can also trigger rooting (Doucet et al., 2007).

Neonatal locomotion: Curiously, very little consideration has been given to emotional, motivational or goal-directed factors in the control of human neonatal locomotion. Despite the paucity of research devoted to examining the effect of breast/milk odor on newborn locomotion, it is well established that within one or two hours after birth human newborns are able to orient and crawl toward their mother's breast when positioned prone on her abdomen (e.g., Widström et al., 1987, 2011; Righard \& Alade, 1990; Varendi, Porter \& Winberg, 1994). Breast crawling can be elicited by multiple stimuli from the mother. For example, Varendi and Porter (2001) showed that newborns crawled a greater distance on a pediatric mattress when exposed to a pad infused with the maternal breast odor compared to a control odor (water) when the pads were placed $17 \mathrm{~cm}$ in front of the infant. The greater distance was evident after minute two of the three-minute trials. However, as the characteristics of the infants' displacements were not reported, it is not known how the newborns organized their prone progression in the two conditions.

One of the difficulties associated with studying newborn crawling on a surface has been the lack of a method, until recently, that enables the newborn to express its full capabilities, without assistance from an experimenter. We describe such a method in the next section. 


\section{A Mini Skateboard to promote independent quadrupedal crawling in the newborn}

Forma and colleagues (2019) introduced a new method to promote the expression of independent crawling in human newborns that features a mini skateboard, the Crawliskate ${ }^{\circledR}$. The device conforms to the newborn's unique morphology in a way that supports the head in a slightly flexed position and encourages a natural lengthening of the spine while simultaneously raising the head and the trunk off the ground and freeing the arms. Comfortably and securely wrapped on the mini skateboard, the newborn can not only move its arms, head, trunk, and limbs, but also propel itself in any direction thanks to small ball-bearing-style wheels secured to the underside of the skateboard deck. A comparison of the crawling patterns of 2-day-old newborns when they were positioned prone on a pediatric mattress or supported prone on the Crawliskate revealed that newborns travelled significantly further across the surface on the Crawliskate. In addition, they performed significantly more arm movements, engaged in more co-activated movements of the arms and legs, and demonstrated more ipsilateral and contralateral patterns of coordination between the limbs that were representative of mature hands-and-knees crawling when they were positioned on the Crawliskate than when unsupported on the pediatric mattress.

\section{Purpose and Significance of the study}

The current study sought to determine whether human newborns, when secured on the Crawliskate, would modify their quadrupedal locomotion when they smelled the breast/milk odor of their mother compared to a control odor (water). We also sought to determine whether newborns would increase their head rooting movements in the presence of the maternal odor and how these rooting movements would interact with the expression of crawling movements.

In line with previous research (see Loos, Reger \& Schaal 2019 for a review), we hypothesized that maternal odors would have two effects: 1) calm the newborns and consequently decrease their locomotor movements (see also Schaal et al., 1980), and 2) consistent with Varendi and Porter's (2001) findings, increase the distance traveled across the mattress. Consequently, the locomotor movements in the maternal odor condition would be more effective and more efficient than in the control odor condition. We were uncertain how this effectiveness and efficiency would be instantiated in motor terms. Finally, we expected to see an increase in the number and potentially the amplitude of the rooting movements in the condition in which the newborn could smell the maternal odor.

\section{Method}




\section{Participants}

Participants were newborns who were born at or after 38 weeks gestational age, with a minimum weight of 2,700 g, with uncomplicated births, a minimum Apgar score of 8 at 5 min after birth and no pathologies. In total, 54 newborns were tested in the experiment. However, 12 newborns were excluded because they didn't move in one of the conditions ( 8 in the maternal odor condition and 4 in the control condition) and 4 because they didn't move in both conditions (at least 20 movements per minute are necessary for analysis according to Forma et al., 2019). Eight additional infants were excluded for falling asleep during the experiment and two for technical problems with the recording equipment. The final analyzed sample consisted of 282 day-old newborns ( 11 girls, 17 boys; mean age $=2.63$ days, $S D=0.67$ and mean weight of 3,364 $\mathrm{g}(S D=$ $0.336)$ at birth, mean term of 39.4 weeks $(S D=0.71)$, mean birth size of $49.7 \mathrm{~cm}(S D=1.80)$, and mean birth head circumference $(\mathrm{HC})$ of $35.0 \mathrm{~cm}(S D=1.07)$. The infants were not weighed at test but only newborns who had lost less than $10 \%$ of their birth weight by the test day were permitted by the medical staff to participate in our study. Consequently, we used birth weight to calculate possible correlations with our dependent variables. The participants were predominantly middle class and $20(71 \%)$ were Caucasian. One participant was Asian (4\%). The other 7 (25\%) were of North or Central African descent. All infants were breast-fed and were tested after waking just before feeding. The delay between feeding and testing ranged between 1 to 4 hours. All infants were in stage 3 (eyes open, no movements) on Prechtl's (1974) arousal scale just prior to testing. The study was approved by the ethics committee (Comité de Protection des Personnes) Ile de France 3 CPP under $n^{\circ} \mathrm{Am} 7226-6-2333$, and all parents provided written informed consent prior to their newborn's participation in the study.

\section{Materials and Apparatus}

The primary piece of the apparatus was an $8-\mathrm{cm}$ high $\mathrm{x} 1-\mathrm{m}$ wide $\mathrm{x} 1.6-\mathrm{m}$ long pediatric mattress placed on a 1-m high x 1-m wide x 2-m long table surrounded by three 5-cm high x 5-cm wide barriers, except on the experimenter's side. The table was surrounded by 8 Qualisys (Göteborg, Sweden) Oqus 100-motion capture cameras that were fixed to the walls and pointed toward the center of the mattress. The capture volume was larger than the size of the pediatric mattress. Two Sony (Sony Corporation, Tokyo) Handicam hdr-cx 160 HD video cameras were positioned on either side of the mattress at a height of $1.6 \mathrm{~m}$ to capture the left and right sides of the infant. The video cameras were synchronized with the motion capture cameras through the use of Qualisys Track Manager (QTM) software. 
To allow the newborns to propel themselves with arms and legs in a prone position, the infants were secured snuggly onto the Crawliskate, similar to the one used in the study of Forma et al. (2019). For a more detailed description of the Crawliskate, see Barbu-Roth et al. (2016).

Two odor stimuli were presented to the newborn. In the maternal odor condition, the breast odor of the mother of each newborn was collected 12 hours before the test by asking the mother to continuously wear two pads in her bra, each one covering each nipple/areola area. Mothers were asked to remove the pads and place them in a zip-lock plastic bag if they took a shower or breastfed their newborn. The two pads were collected in this bag 5 minutes before the test of the newborn and only one pad was used during testing. When collected, the mothers' pads weighed a mean of $3.12 \mathrm{~g}(\mathrm{SD}=0.06)$. To approximate the weight and moisture content of the pad used in the odor condition, the control pads were moistened with 500 microliters of bottled mineral water (Volvic) just before the test. The maternal or control odor pad was attached to the surface of the head support of the Crawliskate so the newborn's face was in direct contact with it (see the explanation for this procedure in the footnote*). In order to avoid any odor contamination between each test, the odor pads were not directly fixed to the material that covered the head support, but on a scentless plastic band that covered the material. The plastic band was replaced each time a new odor pad was used (see Figure 1). All manipulations of the pads were performed by an experimenter who wore fresh Vinyl gloves for each manipulation.

\section{Procedure}

The infants were undressed down to an undergarment and a diaper upon arrival at the laboratory. Different-sized elastic bands were used to place 8 spherical light reflective markers on the newborn's legs and arms. Two were placed on the lateral malleoli of the ankles, two were placed on the lateral epicondyles of the femurs to mark the knees, two on the lateral epicondyles of the humerus to mark the elbow, and two to the styloid processes of the ulna to mark the wrist. Five additional trunk markers were placed on the wrapping system of the Crawliskate directly above anatomical landmarks. One marker was placed dorsal to the acromion process of each shoulder, one dorsal to each acetabulum of the pelvis, and one on the upper part of the back (closest to C7 vertebrae). The infants also wore a cap with 3 head markers; two were placed laterally, slightly above the ears, and one centrally, at the top of the forehead (see Figure 1).

This article is protected by copyright. All rights reserved 


\section{Conditions}

The newborns were tested in two randomly-ordered 2.5-min conditions (with a 5- to 10min break between conditions): (1) crawling on the Crawliskate with a pad infused with the maternal odor (Maternal condition: M), and (2) crawling on the Crawliskate with a pad moistened with water (Control condition: C).

To avoid any contamination of the infant's nose with previous odor coming from the environment or a previous trial, the newborn's face was gently cleaned with a new pad infused with mineral water (Volvic) 2 minutes before each trial by an experimenter wearing a new pair of Vinyl gloves. Then, one of the pads was attached to the head support of the Crawliskate. At the beginning of each trial, the lead experimenter placed the infant on the Crawliskate and stood behind him/her during the entire trial to ensure safety (without touch). The second experimenter operated a computer that was used to manage the data collection process and positioned $1.5 \mathrm{~m}$ behind the experimental table. The mother sat approximately $1 \mathrm{~m}$ behind the table out of sight of her infant and was asked not to speak during the trial. The overhead lights were switched off to minimize brightness. Throughout the series of experiments, the room temperature was maintained between 24 and $25^{\circ} \mathrm{C}$.

\section{Data Capture and Conditioning for Three Dimensional Kinematic Analyses}

The 16 light-reflective markers were sampled at $60 \mathrm{~Hz}$. The data were filtered with a $3-\mathrm{Hz}$ Butterworth filter and gap filling was done for all gaps smaller than 15 frames using a linear interpolation. If at least one limb marker or trunk or head marker was tracked less than $50 \%$ of the trial before gap filling, we excluded the participant from all kinematic analyses. Consequently, 4 participants were removed from the analyses of movement amplitudes, velocities, displacement and head movements (24 infants were included in the analysis).

\section{Data Reduction}

\section{Coding the leg and arm movements}

We used the method described by Forma et al. (2019) to code arm and leg movements. This method defines two types of movements: 1) leg and arm steps, and 2) leg kicks or arm pumps. The steps, which were considered locomotor movements, were characterized by a movement forward or backward of the hand or the knee consistent with a flexion or extension of the limb that would aid propulsion. The kicks of the legs and pumps of the arms were considered locomotor movements that were aborted and that wouldn't aid propulsion. Leg kicks were characterized by an opening or a closing of the knee angle without a displacement of the knee. The 
arm pumps were characterized by vertical movements of the hand or elbow without concomitant displacement forward or backward of the hand. (see Figure 2 for a depiction of the different movement types).

\section{Coding the crying duration}

Crying duration was determined from the video recording to measure the arousal of the infant during the two trials. Siekerman et al. (2015) showed that crying duration is strongly correlated with the excitation state of the infant as measured by Thelen's arousal scale (Thelen, Fisher \& Ridley-Johnson, 1984). This coding was done to ensure the infant was not overly aroused in one of the two conditions. We also determined the latency of crying by noting the time between the first frame of the trial and the first frame of the first period of crying in the trial.

\section{Interrater reliability}

A primary coder coded all of the trials using a two-stage process. First, the primary coder coded $20 \%$ of the trials. Second, the primary coder re-coded the same $20 \%$ of the trials to establish within-coder reliability. At the same time, a secondary (experienced) coder coded the same $20 \%$ of trials to establish between-coder reliability. Intraclass correlation coefficients were calculated for each variable analyzed to determine agreement between the two sets of coding performed by the primary coder and between the primary and secondary coders. Both coders were blind to the nature of the stimulus condition. To avoid the possibility of the coders comparing the crawling pattern across conditions, each trial for each infant was assigned a randomly generated code. The coding was then performed randomly across trials and infants to minimize the potential bias associated with knowing how an infant had performed in the other condition. The within-coder intraclass correlation coefficients were high for the movement variables, ranging from 0.90 to 0.98. The between-coder correlation coefficients were also high, ranging from 0.82 to 0.88 across all movement variables. For the crying duration, the within-coder correlation coefficients were 0.98 to 1 and the between-coder correlation coefficients were between 0.96 and 0.98 . Consequently, the primary coder then coded the remaining $80 \%$ of trials. The recoded $20 \%$ of trials and the subsequently coded $80 \%$ of trials from the primary coder were ultimately subjected to analysis.

\section{Duration, amplitude and velocity of the flexion and extension of the step movements}

We used the video data to determine the duration of each extension or flexion movement of the leg or arm step, and we used the video and motion capture data to determine their amplitudes 
and maximum velocities (Vmax). The durations of flexion and extension corresponded to the time between the start and the end of the coded movement. The amplitudes corresponded to the mean displacements of the two markers of the concerned limb between the start and the end of the movement. Velocities represented the peak velocity (Vmax) of the two markers attached to each limb during the movement.

\section{Displacement during crawling}

The effective displacement (Dxy) was determined by measuring the distance traveled by the center of mass of the newborn in the XY horizontal plane of the mattress between the first frame and the last frame of the trial. The value was positive if the newborn moved forward or negative if $\mathrm{s} / \mathrm{he}$ moved backward.

\section{Coactivation of the flexion and extension of the arm and leg movements}

To determine if the four limbs moved together and whether flexions and extensions were coactivated, we used the method described by Forma et al. (2019). We calculated two measures for each of the 6 possible pairs of limbs: leg pairs, arm pairs, ipsilateral pairs (left arm-left leg and right arm-right leg), and diagonal pairs (left arm-right leg and right arm-left leg). First, we calculated the quantity of coactivation (QC), which is the proportion of time two limbs moved together across the trial. Second, we calculated the percentage of in-phase vs. anti-phase coupling across the coactivation periods for each pair of limbs.

\section{Head rooting movements}

The goal of this analysis was to determine if the newborn would make more head rooting movements when the pad under her face carried the maternal odor. To quantify the small lateral displacements of the head characteristic of the rooting movements, we extracted the roll of the head (rotation around the cephalo-caudal axis) from the motion capture data during each trial. The head movements were characterized relative to the trunk. We calculated two variables: first, the number of head rooting movements and second, the average amplitude of the rooting movements. A rooting movement was counted each time the head crossed a virtual line representing the midsagittal plane (designated as 0 degrees) defined by the newborn's nose aligned with the midline of the body axis (cephalo-caudal axis). We also integrated two thresholds to count a rooting movement. The minimum threshold was a movement greater than 3 degrees to remove all small random rotations associated with noise in the data signal. The maximum threshold was 50 degrees to eliminate any head movement associated with an orientation of the face completely to the left or right and not touching the pad. These thresholds led to the detection of bursts of rooting 
movements that showed very high correspondence with bursts of rooting that were identified from qualitative analyses of the video data. The correspondence was determined by inspecting the time codes on the videos when bursts of rooting were identified qualitatively and comparing them to the time codes on the times series of kinematic data used to identify bursts of rooting. Only one newborn in the maternal condition and two newborns in the control condition performed an obvious rooting behavior on the video recordings, but had their cheek resting on the surface of the Crawliskate, impeding the 3D kinematic identification of their rooting. In these 3 trials only, the number of rooting movements was replaced by the mean value obtained in each corresponding condition. Three newborns were excluded from the analysis of the amplitude of the rooting movements because they did not perform any rooting movements in the control condition (21 infants were included in the analysis).

\section{Co-occurrence of rooting and stepping movements}

When infants display the bilateral head sweeping actions that constitute rooting, their facial (tactile, olfactory, visual) sensors may elicit an attentional capture that inhibits other motor outputs. To assess if the rooting behavior influenced locomotor behavior, we calculated the correlation between the number of rooting movements and the number of steps as well as the correlation between the number of rooting movements and the traveled distance. We also examined the temporal/sequential organization of rooting and stepping by analyzing the overlap of their periods of activity. This analysis was performed by calculating the quantity of co-occurrences of both behaviors, which was the proportion of frames a leg or arm step and a rooting movement occurred together across the trial. Three subjects were excluded from the analysis because they did not perform any rooting movements in the control condition (21 infants were included in the analysis). 


\section{Data Analysis}

The statistical analyses were conducted with Statistica ${ }^{\circledR}$ software (version 6.1). According to the Kolmogorov-Smirnov test, all the data were normally distributed. The number of crawling movements was analyzed with a 2 Condition (Maternal or Control) x 2 Movement Type (Step or Kick/Pump) x 2 Limb (Leg or Arm) repeated-measures analysis of variance (ANOVA). Because of the small number of kick/pump movements, we only analyzed the amplitudes, max velocities and durations of the step movements, using a 2 Condition (Maternal or Control) x 2 Limb (Leg or Arm) repeated-measures ANOVA. The distances, head rooting movements, the crying duration and the latency before crying were analyzed using Student's t-tests. The quantity of coactivations, and the in-phase vs. anti-phase coactivations were analyzed with a 2 Condition x 6 Limb Pair (Ipsilateral: left arm/left leg and right arm/right leg, Diagonal: left arm/right leg and right arm/left leg, Leg: left leg/right leg and Arm: left arm/right arm) repeated-measures ANOVA. The cooccurrence between stepping and rooting movements was analyzed with a Student's t-test. A Tukey HSD post hoc test was used to follow up significant interaction effects. Finally, a correlation matrix was constructed to determine the associations between the independent and dependent variables in the study and an ANCOVA was conducted to verify the effect of Term on the number of steps. In addition, we constructed a correlation matrix between all the variables in the study to check for threats to the validity of the findings.

\section{Results}

\section{Effect of Maternal odor}

Table 1 provides a summary of the dependent measures in each of the conditions.

Number of Arm and Leg movements. Newborns produced fewer arm and leg step movements in the Maternal condition than in the Control condition. The 2 Condition $\mathrm{x} 2$ Movement type x 2 Limb repeated measures ANOVA revealed a significant interaction between Condition and Movement Type $\left(\mathrm{F}_{(1,27)}=5.0, \mathrm{p}=0.034, \eta_{\text {partial }}^{2}=0.16\right)$. The post hoc comparison showed that significantly fewer steps were made in the Maternal condition $(p=0.016)$ (see Figure 3). The number of leg kicks and arm pumps was very low in comparison to the number of steps and not significantly different in the Maternal and Control conditions (see Table 1 and Figure 3).

Displacement during Crawling. The Student's t-test revealed that the newborns displaced themselves significantly further in the Maternal condition (mean $=7.26 \mathrm{~cm} / \mathrm{min}, S D=10.3$ ) than in the Control condition (mean $=4.87 \mathrm{~cm} / \mathrm{min}, S D=8.2)(\mathrm{p}=0.045$, Cohen's $d=0.26)$. 
Amplitudes and Velocities of Steps. No significant differences were observed between the Maternal condition and the Control condition for the 2 Condition $\mathrm{x} 2$ Limb repeated measures ANOVA conducted on amplitudes $\left(\mathrm{F}_{(1,23)}=0.00, \mathrm{p}=0.984, \eta_{\text {partial }}^{2}=0.00\right)$ and peak velocities $\left(\mathrm{F}_{(1,23)}=0.21, \mathrm{p}=0.652, \eta_{\text {partial }}^{2}=0.01\right)$ of the steps.

Durations of Steps. The 2 Condition x 2 Limb repeated-measures ANOVA on step durations revealed no significant differences between the Maternal and the Control conditions $\left(\mathrm{F}_{(1,27)}=0.50, \mathrm{p}=0.487, \eta_{\text {partial }}^{2}=0.02\right)$.

Coactivation of the Arm and Leg Movements. The 2 Condition x 6 Limb Pair repeatedmeasured ANOVA's conducted on the quantity of coactivations $\left(F_{(1,27)}=2.1, p=0.157, \eta^{2}\right.$ partial $=$ $0.07)$ and the in-phase vs anti-phase coactivation $\left(\mathrm{F}_{(1,27)}=0.75, \mathrm{p}=0.393, \eta_{\text {partial }}^{2}=0.03\right)$ did not reveal any differences between the two conditions.

Duration and latency of crying. The Student's t-tests did not reveal any significant differences for the duration of crying between the Maternal (mean $=46.44 \mathrm{~s}, S D=12.2)$ and the Control conditions $($ mean $=49.68 \mathrm{~s}, S D=12.1)(\mathrm{p}=0.125$, Cohen's $\mathrm{d}=0.27)$ or for the latency of crying between the Maternal $($ mean $=3.82 \mathrm{~s}, S D=10.9)$ and the Control $($ mean $=2.01 \mathrm{~s}, S D=4.7)$ conditions ( $\mathrm{p}=0.405$, Cohen's $\mathrm{d}=0.22)$.

Head rooting Movements. The Student's t-test revealed that the newborns performed a higher number of rooting movements in the Maternal condition (mean $=37.04 / \mathrm{min}, S D=22.9$ ) than in the Control condition (mean $=26.67 / \mathrm{min}, S D=25.8)(\mathrm{p}=0.031$, Cohen's $d=0.42)$.

Amplitude of the rooting movements. The Student's t-test did not reveal any significant differences in the amplitude of the rooting movements between the Maternal (mean $=6.59^{\circ}, S D=$ 2.0) and the Control conditions (mean $\left.=6.37^{\circ}, S D=1.4\right)(\mathrm{p}=0.18$, Cohen's $d=0.12)$.

Correlation and co-occurrence of the rooting and stepping movements.

To assess if the rooting behavior influenced locomotor behavior, we calculated the correlation between the number of rooting movements and the number of steps and the traveled distance. We did not find a significant correlation between any of the variables $(r=0.16, p=0.287$ for the correlation between the number of rooting movements and the traveled distance and $\mathrm{r}=$ $0.15, p=0.310$ for the correlation between the number of rooting movements and the number of steps). We did not find any significant differences in the sequential organization of the rooting and stepping periods between the Maternal condition and the Control condition ( $\mathrm{p}=0.22$, Cohen's $d=$ 0.28 ) with $38 \%$ of the rooting and stepping periods occurring simultaneously in the Maternal condition versus $33 \%$ in the Control condition. Finally, we did not find any correlation between 
rooting activity and crying $(\mathrm{r}=0.13, \mathrm{p}=0.545)$.

\section{Associations among the condition order and newborn characteristics and the crawling and rooting variables}

We did not find any associations between the size, the weight or the order of the conditions and the number of steps, the characteristics of the steps, the displacement, the coactivation variables or the rooting variables (see Table 2). The term of the newborn was moderately positively correlated with the number of steps $(r=0.429)$. A 2 Condition $x 2$ Limb analysis of covariance (ANCOVA) with Term as a covariate revealed an effect of Term on the number of steps $\left(\mathrm{F}_{(1,26)}=5.8, \mathrm{p}=\right.$ $0.023, \eta_{\text {partial }}^{2}=0.18$ ) with more steps in newborns with the highest term (Figure 4). In addition, the infant's sex was moderately negatively related to the amplitude $(r=-0.412)$ and maximum velocity $(r=-0.472)$ of stepping movements, with males having larger amplitudes and velocities than females. Finally, head circumference was moderately negatively related to the duration of steps $(r=-0.385)$; newborns with smaller heads made steps that were longer in duration. However, none of these correlation values were significant when we controlled for multiple comparisons.

\section{Correlations between all dependent and independent variables}

The correlation matrix between all of the variables is presented in Table 3 (Supplementary Data). Only six correlations were significant when we controlled for the multiple comparisons using the false discovery rate (FDR). These included: the number of step and the coactivation quantity $(r=0.85)$; the number of kick and the duration of step movements $(r=-0.59)$; the sex and the maximum velocity of step movements $(r=-0.65)$; the number and the amplitude of the head rooting movements $(\mathrm{r}=0.75)$; the coactivation ratio of the arms and the coactivation ratio of the left arm and left leg $(r=0.81)$; the infant weight and head circumference $(r=0.63)$. None of these correlations threatened the validity of the findings reported in the results section.

\section{Discussion}

Our study showed that newborns traveled a significantly greater distance, with significantly fewer locomotor steps, and made significantly more head rooting movements when smelling a pad infused with the mother's breast odor compared to a control odor. These findings confirm that newborn crawling is much more complex than a simple reflex as it can be modified by stimuli 
known to be processed cortically. They also add to the growing literature on perception-action coupling in the newborn showing that such coupling appears quite sophisticated, with the same maternal odor inducing different response patterns in crawling and rooting, opening new questions about the mechanisms underlying such effects.

\section{Effect of the maternal odor on newborn quadrupedal locomotion}

The greater distance traveled by the newborns in response to the mother's odor confirms the findings from the Varendi and Porter (2001) study, although in contrast to their method of delivering the odor at a distance from the infant, we presented the odor directly under the nose of the newborn, as is common in studies designed to elicit locomotion in rat pups (Mendez-Gallardo \& Robinson, 2013). Curiously, however, the number of arm and leg steps was actually lower in the maternal odor condition, despite the greater propulsion in this condition. A similar finding of reduced air stepping was reported for rat pups when they were exposed to their nest odor (Jamon et al., 2002). What explanation might account for the fewer arm and leg steps in response to the mother's breast odor? One explanation for this curious finding is that the maternal odor, as a signal of the mother's presence, had a calming effect on the newborn's general motor activity. Such an effect could have been quite pronounced given that the newborn was likely stressed by the experimental context. Indeed, several studies support this observation. For example, Schaal et al. (1980), Doucet et al. (2007) and Nishitani et al. (2009) reported that newborns showed a significant decrease in their general motor activity and delayed crying onset or reduced crying duration when they could smell their mother's breast or milk odor. The same effect has been obtained with a familiar odor that was not the maternal odor (Goubet et al., 2002), indicating that familiarity with the stimulus may explain it. However, the newborns in the present study showed a similar crying duration and latency to cry in the maternal and control odor conditions. The present condition-independent crying behavior likely relates to the pre-feeding stage in which the infants were tested.

Though the decrease in stepping can potentially be explained by a calming effect of the mother's odor, the concomitant increase in the distance traveled in the maternal odor condition is more difficult to explain. This finding clearly suggests that each step was more effective and therefore the whole pattern of locomotion was more efficient. But how was this accomplished given that the steps analyzed in the maternal condition were not larger in amplitude, longer in duration, or higher in velocity? Studies on rat pups found that odor from the nest not only 
diminishes the number of steps but increases ipsilateral limb coordination (Jamon et al., 2002). However, we did not find any differences between conditions in the ipsilateral and contralateral limb coordination and so that variable cannot explain the greater efficiency in the maternal odor condition either.

One possible factor playing a role in increasing the propulsive efficiency of the steps is the position of the foot (and toes) on the mattress. The foot naturally presses against the uterine wall when fetuses make pumping movements with the legs because the foot is aligned (parallel) with the uterine wall. However, newborns must reposition their feet when pushing against a surface on which they are lying prone because the feet are positioned orthogonally relative to the surface. Smelling the maternal odor potentially encouraged a foot position more parallel to the surface, thus inducing a more efficient plantar flexion and better propulsion. The foot position may have changed relative to the surface if the calming effect of the mother's odor lowered the newborns' muscular tonus such that more of each leg's surface area was in contact with the surface of support. Unfortunately, we were not able to investigate this hypothesis as no markers were placed on the feet to capture their motion and the kinematic analyses we performed were not sensitive enough to assess the newborn's level of muscular tonus.

It is also possible that the mother's odor activated a galvanic skin reflex (micro sweating from eccrine sweat glands) on the fingers and toes, leading to better adhesion to the surface, with less slipping on the surface and hence better upper and lower limb propulsion. Emotional sweating from the palms is functional in newborns (e.g., Harpin \& Rutter, 1982; Gladman \& Chiswick, 1990). Unfortunately, again, we did not measure the tackiness of the newborns' hands and feet and so cannot confirm this explanation. Clearly, future studies are needed to understand how newborns adapt their locomotor behavior in response to odors and what factor(s) accounts for why newborns make fewer stepping movements and yet travel greater distances when exposed to their mother's odor compared to a control odor. In any case, the fact that odor increases the efficiency of early locomotion in newborns is a remarkable observation and opens new avenues for exploring the mechanisms that underlie the effect. Interestingly, the rooting behavior of the newborn also significantly increased in response to a pad infused with the maternal odor.

\section{Effect of the maternal odor on newborn rooting}

Studies on the rooting behavior of human newborns typically report the number, duration or latency of rooting bursts observed by video recording (e.g., Takahashi et al., 2015; Glodowski 
et al., 2019; Loos et al., 2019). Here, we report a much more precise technique based on 3D kinematics that quantifies the number of times the head passes through a line representing the midsagittal plane and that limits the amplitude of the rooting movements to a threshold greater than 3 degrees and less than 50 degrees. The significantly greater number of rooting movements in the presence of the mother's breast odor confirms that the newborns could discriminate between the two odor conditions and suggests that they engaged in more searching (for the nipple) in the maternal odor condition.

An interesting question is whether rooting movements influence crawling movements. When infants perform rooting, usually to search for the nipple, they may stop their crawling activity to focus on localizing the nipple. Another possibility is that an attentional capture mechanism is elicited by increased stimulation of the facial sensors (tactile, olfactory, visual), inhibiting other motor outputs. If either was the case, the increased rooting activity observed in the maternal odor condition could explain why fewer steps were seen in that condition compared to the control condition. The rooting response might be an underexploited way to measure differential responses in human newborns to a variety of sensory stimulation. However, we did not find any significant correlations between the number of rooting movements and the number of steps and the traveled distance. Moreover, the co-occurrences and alternations of rooting and stepping were similar in both conditions, suggesting that the reduction in crawling in the maternal condition was not related to the increase in rooting.

\section{What the motor response to maternal odor reveals about the adaptability of early} locomotion and rooting

Evidence for supra-spinal control

Prior evidence already shows that the newborn crawling pattern is adaptable to stimuli that are processed above the level of the spinal cord. For example, Forma et al. (2018) showed that newborns made significantly more leg flexion and extension locomotor movements when they were placed prone on a pediatric mattress and exposed to patterns of optic flow that specified forward and backward translation than when exposed to a static checkerboard pattern. Similarly, Barbu-Roth et al. $(2009,2014)$ have shown that newborns will make more leg stepping movements in the air when supported above a horizontal surface onto which are projected optic flows that specify forward or backward translation across the surface. These findings are relevant to the adaptability of newborn crawling following Barbu-Roth et al.'s $(2009,2014)$ argument that 
stepping is a partial manifestation of the quadrupedal crawling pattern, albeit in a different postural context. This idea was inspired by the observation of arm movements coupled to leg movements when the newborn was suspended in the air by the experimenter in such a way that the arms were not blocked from moving. The idea received further support from a recent study by La Scaleia et al. (2018) in which the same diagonal and ipsilateral couplings between arms and legs were observed, though only sporadically, when newborn stepping was tested in an upright position on a surface.

If higher brain centers are able to modulate spinally-controlled locomotion, as was reported in rat pups (Jamon et al., 2002), what brain centers might be involved in human newborns? From the first days post-birth, artificial odorants elicit hemodynamic brain responses at all levels of the human olfactory tract up to piriform, insular, cingular and orbitofrontal cortices, following the same neural network noted in adults (Adam-Darque et al., 2017; Frie et al., 2017). Such cortical responses have been documented with very low intensity, ecologically-valid odor stimuli such as human milk (Bartocci et al., 2000; Ayoama et al., 2010). Thus, the neonatal brain is ready to process odor cues that were experienced in association with the mother and to control the expression of motor actions at local (head) and general (limbs, whole body) levels indicative of active searching (and otherwise also shown to elicit the behavioral expression of mouthing and licking (Marlier \& Schaal, 2005; Doucet et al., 2007, 2009)). One question that remains open to future investigation is the level of specificity of the mother's breast/milk odor in modulating infant crawling and rooting responsiveness. For example, would the odor of any mother's milk convey the same effects? On the other hand, one may wonder whether any arbitrary odorant associated with the mother (e.g., formula odor, perfume) would be effective in eliciting the pattern of response that was observed in the present study. The odor-related goals of infant's motor activity could be assessed using the present experimental setting by comparing mother-associated odors vs. non-associated odors (i.e., any conventional odorant).

\section{Perception Action Coupling}

The results of this study are consistent with prior studies of perception-action coupling suggesting that newborns have a degree of voluntary control over their movement patterns (e.g., van der Meer et al., 1995; De Casper and Fifer, 1980; Moon et al., 1993). Here, we show that perception-action coupling mobilizes whole-body locomotion as well as head rooting in response to the maternal odor. Hungry breastfed infants may anticipate what is going to happen when they are exposed to the odor of their mother's breast right before the next feed. Learned regularities of 
events suggest breast odor may signal a cascade of percepts, e.g., postural adjustment against mother's warm body, followed by the opportunity to suck and get milk in the mouth. Ultimately, breast odor should be associated with multiple rewards ending in metabolic and psychological satiety. In that context, perceiving breast odor should drive the hungry neonate into a functional state where all motor resources co-operate into forward progression and orientation toward the odor-mediated goal - the nipple - and direct action on it. It is only once they can express full sucking that infants may represent being "at home." But it is inherent to the design of the present experiment, and one of its limitations, that the infants can never reach the expected "home." They cannot complete the full searching sequence, the end of which is grasping/sucking a nipple, and so they continue their rooting and crawling behavior.

Interestingly, the motor strategies newborns used to achieve their odor-mediated goal revealed a nuanced cooperation between rooting and crawling, as we observed bursts of crawling and rooting performed concurrently as well as sequentially. Moreover, the perception-action couplings expressed were different for rooting and crawling, the former showing an increase in the number of movements and the latter showing fewer, but more efficient, movements. In a recent unpublished study, where we replaced the maternal odor with the mother's voice, the newborn showed further evidence of adapted perception-action coupling, reducing its steps with the mother's voice but not modifying its rooting behavior relative to a no-voice control condition.

The increased efficiency of crawling in the maternal odor condition deserves further mention because it mirrors previous findings of increased efficiency in behaviors in response to chemosensory stimuli. For example, when exclusively formula-fed infants (aged 10-14 days) were fed the familiar formula while simultaneously exposed to either mother's milk, formula or water odors, their extractive efficacy (volume ingested/min) was higher with the mother's milk odor. Here, the extractive efficacy in the presence of mother's milk odor could be related to objective properties of the sucking actions in terms of frequency of sucks and negative and positive pressure exerted on the nipple (Mizuno \& Ueda, 2004). Another example of higher efficacy of oromotor actions is the effect mother's milk has, relative to cow milk-based formula or water, on the coordinated expression of swallowing and inspiration (Johnson \& Salisbury, 1975; Mizuno, Ueda \& Takeuchi, 2002). Although the above examples are restricted to oral actions, they highlight the fact that chemosensory cues in mother's breast/milk odor change something about the quality of the motor flow that increases its efficacy and efficiency. 
An open question is how the newborn recalibrates the internal representation of its mother that s/he started to construct as a fetus. At birth, the newborn experiences major changes in the multiple sensory inputs $\mathrm{s} /$ he gets from the mother and major changes in the potential motoric actions in which s/he can engage. Maternal odor should be a major landmark in this recalibration process as maternal odors are pervasive during fetal life and in early infant development. In this regard, it would be interesting to investigate the capacity of the newborn to integrate the face, voice and odor of its mother to crawl toward her.

\section{Clinical implications}

The current findings have implications for the design of interventions to facilitate locomotor development in infants at risk for developmental delay. The most common intervention for such infants involves the training of stepping on a treadmill (see Teulier, Barbu-Roth, \& Anderson, 2014 for a review). However, treadmill training has several limitations. First, researchers and clinicians have advocated that interventions should start as early as possible to take advantage of the window of greatest neuromuscular plasticity in early development (e.g., Ulrich, 2010), yet little evidence exists to suggest that treadmill training could be started as early as birth (though see Siekerman et al., 2015). Second, infant treadmills are not ubiquitous and they can be expensive. Third, treadmill-induced stepping is largely passive because the treadmill does the work of pulling the legs backward, which then spring forward because of the passive-elastic elements in the muscles/tendons that cross the hip joint. Fourth, an experimenter or parent must always be present to support the infant in an upright position. Given these limitations, we argue that crawling may be a much better target for early interventions, particularly if that crawling is supported by an age-adapted device. At the very least, crawling should be used as an adjunct to treadmill training. Crawling has a number of advantages as a target for early interventions: 1) it can be stimulated from birth, 2) it is under the newborn's active control (i.e., it is true locomotion), 3) the newborn does not require support from an experimenter, and 4) the infant's efforts can be easily quantified by the number of steps and the distance travelled.

Another implication of the current findings is that regardless of whether stepping or crawling serves as the basis for intervention, the intervention can potentially be made more effective by adding stimuli to the training context that would normally be present during natural locomotion or that have hedonic value. Optic flow is one stimulus that could enhance an intervention. However, stimuli associated with the mother, such as her odor or voice, may lead to 
even greater enhancement because of their assumed motivational effects on infants. Of course, multiple stimuli could be combined to maximize the effectiveness of an intervention. These implications are speculative, and await future research, but they stem logically from the current set of findings.

\section{FOOTNOTE *}

The most appropriate way to present the odor posed a challenge. In a pilot study, we presented the odors on a pad located $17 \mathrm{~cm}$ in front of the newborns' noses, as was done in the Varendi and Porter (2001) study. However, our newborns did not move as far as Varendi and Porter's newborns and we found no differences in distance traveled between the maternal odor and control odor conditions. As we were not focused on studying the orientation of the newborn toward the odor but on analyzing the effect of this odor on rooting and locomotion patterns, we chose to place the odor-infused pads directly under the nose of the newborns as is common in rat studies (Mendez-Gallardo \& Robinson, 2013).

\section{References}

Adam-Darque, A., Grouiller, F., Vasung, L., Ha-Vinh Leuchter, R., Pollien, P., Lazeyras, F., \& Hüppi, P. S. (2017). Fmri-based neuronal response to new odorants in the newborn brain. Cerebral Cortex, 28(8), 2901-2907. 
Aoyama, S., Toshima, T., Saito, Y., Konishi, N., Motoshige, K., Ishikawa, N., ... \& Kobayashi, M. (2010). Maternal breast milk odour induces frontal lobe activation in neonates: A NIRS study. Early Human Development, 86(9), 541-545.

Barbu-Roth, M., Anderson, D. I., Desprès, A., Provasi, J., Cabrol, D., \& Campos, J. J. (2009). Neonatal stepping in relation to terrestrial optic flow. Child Development, 80(1), 8-14. https://doi.org/10.1111/j.1467-8624.2008.01241.x

Barbu-Roth, M., Anderson, D. I., Desprès, A., Streeter, R. J., Cabrol, D., Trujillo, M., ... Provasi, J. (2014). Air stepping in response to optic flows that move Toward and Away from the neonate. Developmental Psychobiology, 56(5), 1142-1149.

Barbu-Roth, M., Forma, V., Teulier, C., Anderson, D., Provasi, J., \& Schaal, B. (2016). Device for assisting the crawling of an infant. WO/2016/009022. Retrieved from https://patentscope.wipo.int/search/en/detail.jsf?docId=WO2016009022\&recNum=\&maxRe $\mathrm{c}=1000$ \&office $=\&$ prevFilter $=\&$ sortOption $=\&$ queryString $=\&$ tab $=$ PCTBiblio

Bartocci, M., Winberg, J. A. N., Ruggiero, C., Bergqvist, L. L., Serra, G., \& Lagercrantz, H. (2000). Activation of olfactory cortex in newborn infants after odor stimulation: a functional near-infrared spectroscopy study. Pediatric Research, 48(1), 18.

Bobin-Bègue, A., Provasi, J.,Marks,A., and Pouthas,V. (2006). Influence of auditory tempo on the endogenous rhythm of non-nutritive sucking. Rev. Eur. Psychol. Rev. Appl. Psychol. 56,239245. doi:10.1016/j.erap.2005.09.006

Craig CM, Lee DN (1999) Neonatal control of sucking pressures: evidence for an intrinsic t-guide. Exp Brain Res 124:371-382

DeCasper, A. J., \& Fifer,W. P. (1980). Of human bonding: Newborns prefer their mothers' voices. Science, 208, 1174-1176.

Doucet S., Soussignan R., Sagot P., \& Schaal B. (2007). The "smellscape" of the human mother's breast: effects of odour masking and selective unmasking on neonatal arousal, oral and visual responses. Developmental Psychobiology, 49, 129-138. 
Doucet S., Soussignan R., Sagot P., \& Schaal B. (2009). The secretion of areolar (Montgomery's) glands from lactating women elicits selective, unconditional responses in neonates. PLoS ONE 4:e7579.

Forma, V., Anderson, D. I., Goffinet, F., \& Barbu-Roth, M. (2018). Effect of optic flows on newborn crawling. Developmental Psychobiology, 60, 497-510. https://doi.org/10.1002/dev.21634

Forma, V., Anderson, I. D., Provasi, J., Soyez, E., Martial, M., Huet, V., Granjon, L., Goffinet, F., \& Barbu-Roth, M. (2019). What Does Prone Skateboarding in the Newborn Tell Us About the Ontogeny of Human Locomotion? Child Development, 90(4), 1286-1302. doi : $10.1111 /$ cdev.13251

Frie, J., Bartocci, M., Lagercrantz, H., \& Kuhn, P. (2017). Cortical responses to alien odors in newborns: a fNIRS study. Cerebral Cortex, 28(9), 3229-3240.

Gentry, E. F., \& Aldrich, C. A. (1948). Rooting reflex in the newborn infant: Incidence and effect on it ofsleep.American Journal of Diseases of Children, 75(4),528-539. Doi: 10.1001/archpedi.1948.02030020543003

Gladman, G., \& Chiswick, M. L. (1990). Skin conductance and arousal in the newborn. Archives of Disease in Childhood, 65(10 Spec No), 1063-1066.

Glodowski, K. R., Thompson, R. H., \& Martel, L. (2019). The rooting reflex as an infant feeding cue. Journal of Applied Behavior Analysis, 52(1), 17-27.

Goubet, N., Rattaz, C., Pierrat, V., Alléman, V., Bullinger, A., \& Lequien, A. (2002). Olfactory familiarisation and discrimination in preterm and full-term newborns. Infancy, 3, 53-75.

Grenier A. Expression of liberated motor activity (LMA) following manual immobilization of the head. In: Amiel-Tison C, Grenier A, eds. Neurological Evaluation of the Newborn and the Infant. New York, NY: Masson; 1983:87-109.

Harpin, V. A., \& Rutter, N. (1982). Development of emotional sweating in the newborn infant. Archives of Disease in Childhood, 57(9), 691-695. 
Jamon, M., Maloum, I., Riviere, G., \& Bruguerolle, B. (2002). Air-stepping in neonatal rats: A comparison of L-dopa injection and olfactory stimulation. Behavioral Neuroscience, 116, 1014-1021. doi: 10.1037/0735-7044.116.6.1014

Johnson, P., \& Salisbury, D. M. (1975). Breathing and sucking during feeding in the newborn. Ciba Foundation Symposia, 33, 119-135.

La Scaleia, V., Ivanenko, Y., Fabiano, A., Sylos-Labini, F.,Cappellini, G., Picone, S., Paolillo P., Di Paolo A., Lacquaniti, F. (2018). Early manifestation of arm-leg coordination during stepping on a surface in human neonates. Experimental Brain Research, 236, 1105-1115. https://doi.org/10.1007/s00221-018-5201-y

Loos, H. M., Reger, D. \& Schaal, B. (2019). The odour of human milk: its chemical variability and detection by newborns. Physiology \& Behavior, 199, 88-99.

Marlier, L, \& Schaal, B. (2005). Human newborns prefer human milk: Conspecific milk odor is attractive without postnatal exposure. Child Develoment, 76:155-168.

Mendez-Gallardo, V., \& Robinson, S. R. (2013). Odor-induced crawling locomotion in the newborn rat: effects of amniotic fluid and milk. Developmental. Psychobiology, 56, 327-339. Doi: $10.1002 / \mathrm{dev} .21102$

Mizuno, K., Ueda, A., \& Takeuchi, T. (2002). Effects of different fluids on the relationship between swallowing and breathing during nutritive sucking in neonates. Neonatology, 81(1), 45-50.

Mizuno, K., \& Ueda, A. (2004). Antenatal olfactory learning influences infant feeding. Early human development, 76(2), 83-90.

Moon, C., Cooper, R. P., \& Fifer, W. P. (1993). Two-day-old infants prefer their native language. Infant Behavior \& Development, 16, 495-500.

Molina, M., \& Jouen, F. (1998). Modulation of the palmar grasp behavior in neonates according to texture property. Infant Behavior \& Development, 21(4), 659666. https://doi.org/10.1016/S0163-6383(98)90036-4

Nishitani, S., Miyamura, T., Tagawa, M., Sumi, M., Takase, R., Doi, H., Moriuchi, H., \& Shinohara, K. (2009). The calming effect of a maternal breast milk odor on the human 
newborn infant. Neuroscience $\quad$ Research, 66-71, https://doi.org/10.1016/j.neures.2008.10.007.

Papoušek, H. (1961). Conditioned Head Rotation Reflexes in Infants in the First: Months of Life. Acta Paediatrica, 50(6), 565-576.

Prechtl, H. F. R. (1958). The directed head turning response and allied movements of the human baby. Behaviour, 13, 212-242.

Prechtl, H. F. R. (1974). The behavioural states of the newborn infant (a review). Brain Research, 76(2), 185-212. https://doi.org/10.1016/0006-8993(74)90454-5

Righard, L., \& Alade, M. O. (1990). Effect of delivery room routines on success of first breastfeed. Lancet, 336, 1105-1107.

Rochat, P., \& Hespos, S. J. (1997). Differential rooting response by neonates: Evidence for an early sense of self. Early Development and Parenting, 6, 105-112. Doi: 10.1002/(SICI)10990917(199709/12)6:3/4<105:AID-EDP150>3.0.CO;2-U

Rönnqvist, L., Von Hofsten, C. (1994). Neonatal Finger and Arm Movements as Determined by a Social and an Object Context. Early Development and Parenting, Vol. 3 (2), 81-94

Schaal, B., Montagner, H., Hertling, E., Bolzoni, D., Moyse, R., \& Quichon, R. (1980). Les stimulations olfactives dans les relations entre l'enfant et la mère [Olfactory stimulations in mother-infant relationships]. Reproduction, Nutrition, Development, 20:843-858.

Schaal, B., Hummel, T., \& Soussignan R. (2004). Olfaction in the fetal and premature infant: Functional status and clinical implications. Clinics in Perinatalogy, 31, 261-285.

Schaal B, Saxton TK, Loos H, Soussignan R, Durand K. (2020). Olfaction scaffolds the developing human from neonate to adolescent and beyond. Phil. Trans. R. Soc. B 375: 20190261. http://dx.doi.org/10.1098/rstb.2019.0261

Siekerman, K., Barbu-Roth, M., Anderson, D. I., Donnelly, A., Goffinet, F., \& Teulier, C. (2015). Treadmill stimulation improves newborn stepping. Developmental Psychobiology, 57(2), 247-254. https://doi.org/10.1002/dev.21270 
Takahashi, Y., Jonas, W., Ransjö-Arvidson, A. B., Lidfors, L., Uvnäs Moberg, K., \& Nissen, E. (2015). Weight loss and low age are associated with intensity of rooting behaviours in newborn infants. Acta Paediatrica, 104(10), 1018-1023.

Thelen, E., Fisher, D. M., \& Ridley-Johnson, R. (1984). The relationship between physical growth and a newborn reflex. Infant Behavior and Development, 7(4), 479-493. https://doi.org/10.1016/S0163-6383(84)80007-7

Teulier, C., Barbu-Roth, M., \& Anderson, D. (2014). Treadmill training in early infancy: sensory and motor effects. In R. B. Shepherd (Ed.), Cerebral palsy in infancy (pp. 275-289). Amsterdam, the Netherlands: Elsevier.

Ulrich, B. D. (2010). Opportunities for early intervention based on theory, basic neuroscience, and clinical science. Physical Therapy, 90(12), 1868-1880. https://doi.org/10.2522/ptj.20100040

Van der Meer, A. L. H., Van der Weel, F. R., Lee, D. N. (1995). The functional significance of arm movements in neonates. Science 267, 693-695. https://doi.org/10.1126/science.7839147

Varendi, H., Porter, R. H., \& Winberg, J. (1994). Does the newborn baby find the nipple by smell? Lancet, 344, 989-990.

Varendi, H., \& Porter, R. H. (2001). Breast odour as the only maternal stimulus elicits crawling towards the odour source. Acta Pediatrica, 90, 372-375.

Von Hofsten C. (1982). Eye-Hand coordination in the newborn. Developmental Psychology,18,2,450-461.

Widström A.M., Ransjö-Arvidson A.B., Christensson K., Matthiesen A.-S., Winberg J., UvnäsMoberg K. (1987). Gastric suction in healthy newborn infants : effects on circulation and developing feeding behavior. Acta Paedriatrica, 76(4): 566-572.

Widström, A. M., \& Thingström-Paulsson, J. (1993). The position of the tongue during rooting reflexes elicited in newborn infants before the first suckle. Acta Paediatrica, 82(3), 281-283.

Widström, A. M., Lilja, G., Aaltomaa-Michalias, P., Dahllöf, A., Lintula, M., \& Nissen, E. (2011). Newborn behaviour to locate the breast when skin-to-skin: a possible method for enabling early self-regulation. Acta Paediatrica, 100(1), 79-85.

Wolff, P. H. (1959). Observations on newborn infants. Psychosomatic Medicine, 21, 110-118. 
Table 1. Mean and standard deviations for the variables measured in infants alternately exposed to their mother's breast odor (M) and to a control odor (C).

\begin{tabular}{|c|c|c|c|c|c|c|}
\hline \multirow[b]{3}{*}{ Variables } & \multicolumn{4}{|c|}{ Conditions } & \multirow[b]{3}{*}{$\mathrm{N}$} & \multirow[b]{3}{*}{$\mathrm{p}$} \\
\hline & \multicolumn{2}{|c|}{$\mathbf{M}$} & \multicolumn{2}{|c|}{$\mathbf{C}$} & & \\
\hline & Mean & $(S D)$ & Mean & $(S D)$ & & \\
\hline \multicolumn{7}{|l|}{ Number of Movements/min } \\
\hline Step (Leg and Arm) & 9.62 & (3.7) & 10.95 & (4.1) & 28 & 0.016 \\
\hline Kick/Pump (Leg and Arm) & 2.19 & (1.2) & 2.22 & (1.1) & 28 & 0.853 \\
\hline Amplitude of Step Movements $(\mathrm{mm})$ & 33.45 & (8.0) & 33.43 & (7.7) & 24 & 0.984 \\
\hline MaxVelocity of Step Movements $(\mathrm{mm} / \mathrm{s})$ & 152.06 & (26.8) & 154.43 & (29.3) & 24 & 0.652 \\
\hline Duration of Step Movements $(s)$ & 0.77 & $(0.2)$ & 0.76 & $(0.2)$ & 28 & 0.487 \\
\hline Traveled Distance $(\mathrm{cm} / \mathrm{min})$ & 7.26 & (10.3) & 4.87 & (8.2) & 24 & 0.045 \\
\hline \multicolumn{7}{|l|}{ Head Rooting movements } \\
\hline Number of the rooting Movements & 37.04 & (22.9) & 26.67 & (25.8) & 24 & 0.031 \\
\hline Amplitude of the rooting Movements $\left({ }^{\circ}\right)$ & 6.59 & (2.0) & 6.37 & (1.4) & 21 & 0.180 \\
\hline \multicolumn{7}{|l|}{ Coactivation } \\
\hline Quantity & 0.14 & $(0.1)$ & 0.16 & (0.1) & 28 & 0.157 \\
\hline Coactivation ratio (CR) & 0.00 & $(0.1)$ & -0.02 & $(0.1)$ & 28 & 0.393 \\
\hline \multicolumn{7}{|l|}{ Coactivation ratio (CR) } \\
\hline Legs CR & -0.20 & $(0.3)$ & -0.24 & (0.4) & 28 & 0.529 \\
\hline Arms CR & 0.10 & $(0.3)$ & 0.09 & $(0.2)$ & 28 & 0.845 \\
\hline AL-LL pair CR & 0.19 & $(0.2)$ & 0.13 & $(0.2)$ & 28 & 0.198 \\
\hline AR-LR pair CR & 0.25 & $(0.2)$ & 0.19 & $(0.2)$ & 28 & 0.320 \\
\hline AL-LR pair CR & -0.19 & $(0.2)$ & -0.19 & $(0.2)$ & 28 & 0.900 \\
\hline AR-LL pair CR & -0.13 & $(0.2)$ & -0.08 & $(0.2)$ & 28 & 0.260 \\
\hline
\end{tabular}


Co-occurrence of the rooting and

stepping movements (\%)

$\begin{array}{llllll}38 \% & (18 \%) & 33 \% & (18 \%) & 25 & 0.224 \\ 46.44 & (12.2) & 49.68 & (12.1) & 28 & 0.167 \\ 3.82 & (10,9) & 2.01 & (4,7) & 28 & 0.405\end{array}$

$\begin{array}{lcccccc}\text { Crying duration }(\mathrm{s} / \mathrm{min}) & 46.44 & (12.2) & 49.68 & (12.1) & 28 & 0.167 \\ \text { Latency of crying }(\mathrm{s}) & 3.82 & (10,9) & 2.01 & (4,7) & 28 & 0.405\end{array}$

The $\mathrm{p}$ values are calculated from ANOVAs for number of movements, amplitudes, max velocities, durations and coactivation variables. The $\mathrm{p}$ values for traveled distance, rooting head movements, crying duration, latency of crying and co-occurrence of the rooting and stepping movements are calculated with paired t tests (when the distribution is normal according to K.S. test) or Wilcoxon tests (when the distribution is not normal according to K.S. test). For the number of step, kick and pump movements, amplitudes, max velocities and durations results are collapsed across leg and arm, left and right sides, flexions and extensions. For the coactivations, results are collapsed across the pairs of limbs.

Table 2. Correlations among the independent and dependent variables

\begin{tabular}{|c|c|c|c|c|c|c|c|}
\hline Variables & Sex & Size & Weight & $\begin{array}{c}\text { Head } \\
\text { circumference }\end{array}$ & $\begin{array}{l}\text { Condition } \\
\text { order }\end{array}$ & Term & \multirow[t]{2}{*}{$\mathrm{N}$} \\
\hline & \multicolumn{6}{|c|}{$\mathrm{r}$} & \\
\hline Number of Step Movements & -0.133 & 0.349 & -0.030 & 0.168 & 0.819 & 0.429* & 28 \\
\hline Amplitude of Step Movements & $-0,412 *$ & 0.343 & 0.046 & 0.093 & -0.320 & -0.068 & 24 \\
\hline MaxVelocity of Step Movements & $-0.472 *$ & 0.205 & 0.169 & 0.196 & -0.241 & 0.177 & 24 \\
\hline Duration of Step Movements & 0.052 & 0.039 & -0.239 & $-0.385 *$ & -0.069 & -0.359 & 28 \\
\hline Traveled distance & -0.229 & -0.005 & -0.053 & 0.032 & -0.344 & 0.343 & 24 \\
\hline Coactivation & & & & & & & \\
\hline Quantity & -0.120 & 0.331 & -0.163 & 0.011 & -0.183 & 0.226 & 28 \\
\hline Coactivation ratio (CR) & 0.048 & 0.313 & 0.082 & -0.162 & -0.124 & 0.110 & 28 \\
\hline $\begin{array}{c}\text { Number of head rooting } \\
\text { Movements }\end{array}$ & -0.105 & 0.036 & 0.034 & 0.197 & -0.219 & 0.365 & 24 \\
\hline
\end{tabular}

$*=\mathrm{p}<0.05$. The $\mathrm{r}$ values are calculated from a correlation matrix between the dependent variables (number, amplitude, max velocity and duration of the steps, traveled distance, coactivation variables and number of rooting movements: results were 
collapsed across the conditions) and the independent variables (size, weight, head circumference, term). For the two categorical variables (sex and condition order), we used a point biserial correlation.

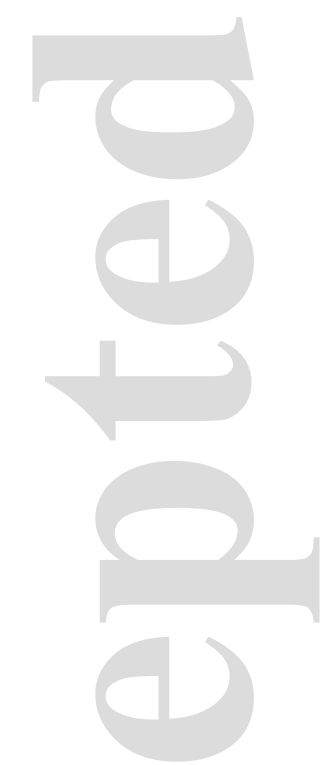

Figure legends

Figure 1

2-day-old infant crawling on the Crawliskate ${ }^{\circledR}$ with motion capture markers in 3D and 2D.

This article is protected by copyright. All rights reserved 
Figure 2

Coded flexion and extension for legs and arms and for Step and Kick/Pump movements.

\section{Figure 3}

Number of leg and arm movements in the Maternal (M) and Control (C) condition. The * symbol indicates the difference between conditions was significant at the 0.05 level and the *** symbol indicates the difference was significant at the 0.001 level.

\section{Figure 4}

Effect of term on the number of step movements 


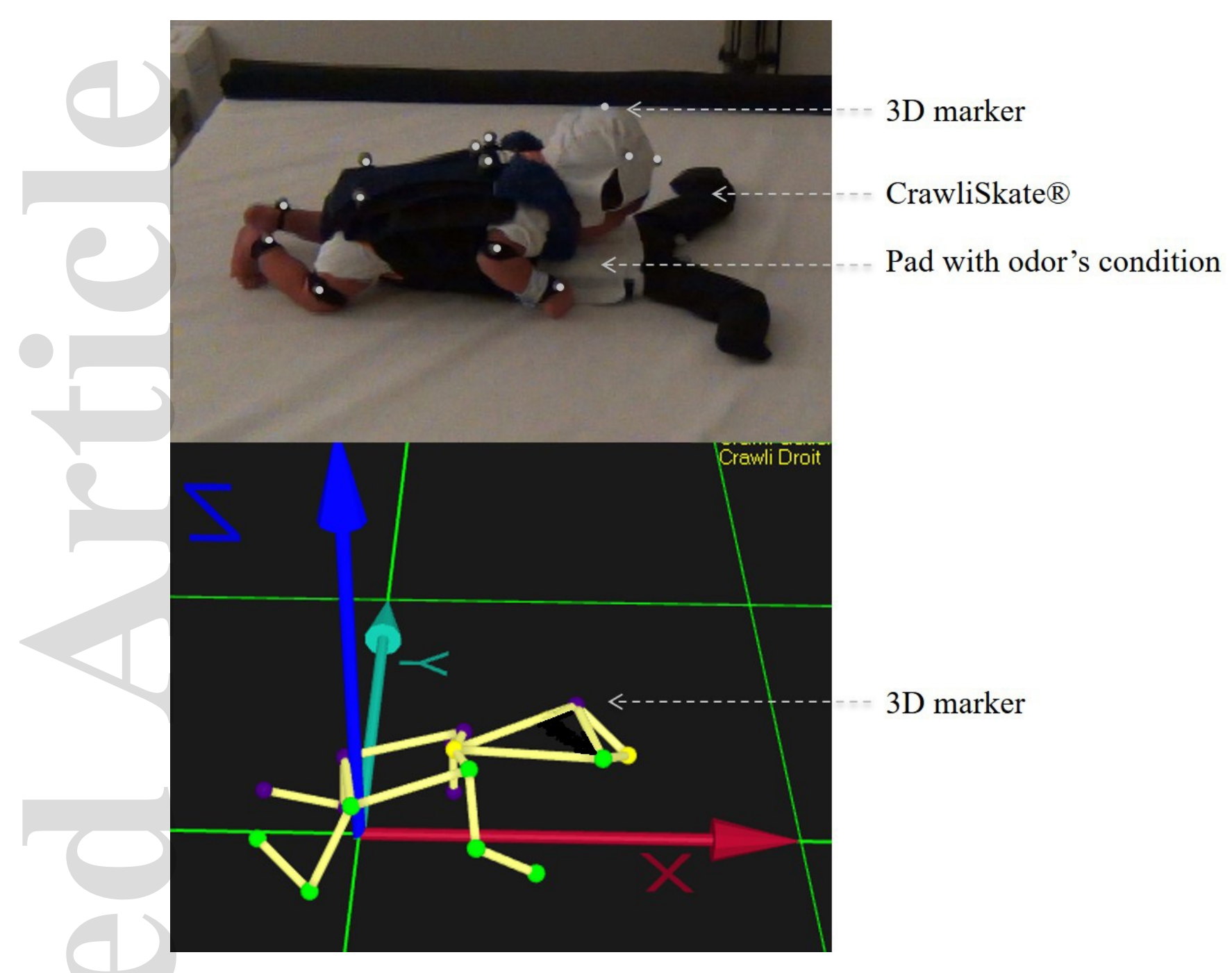

Figure 1 

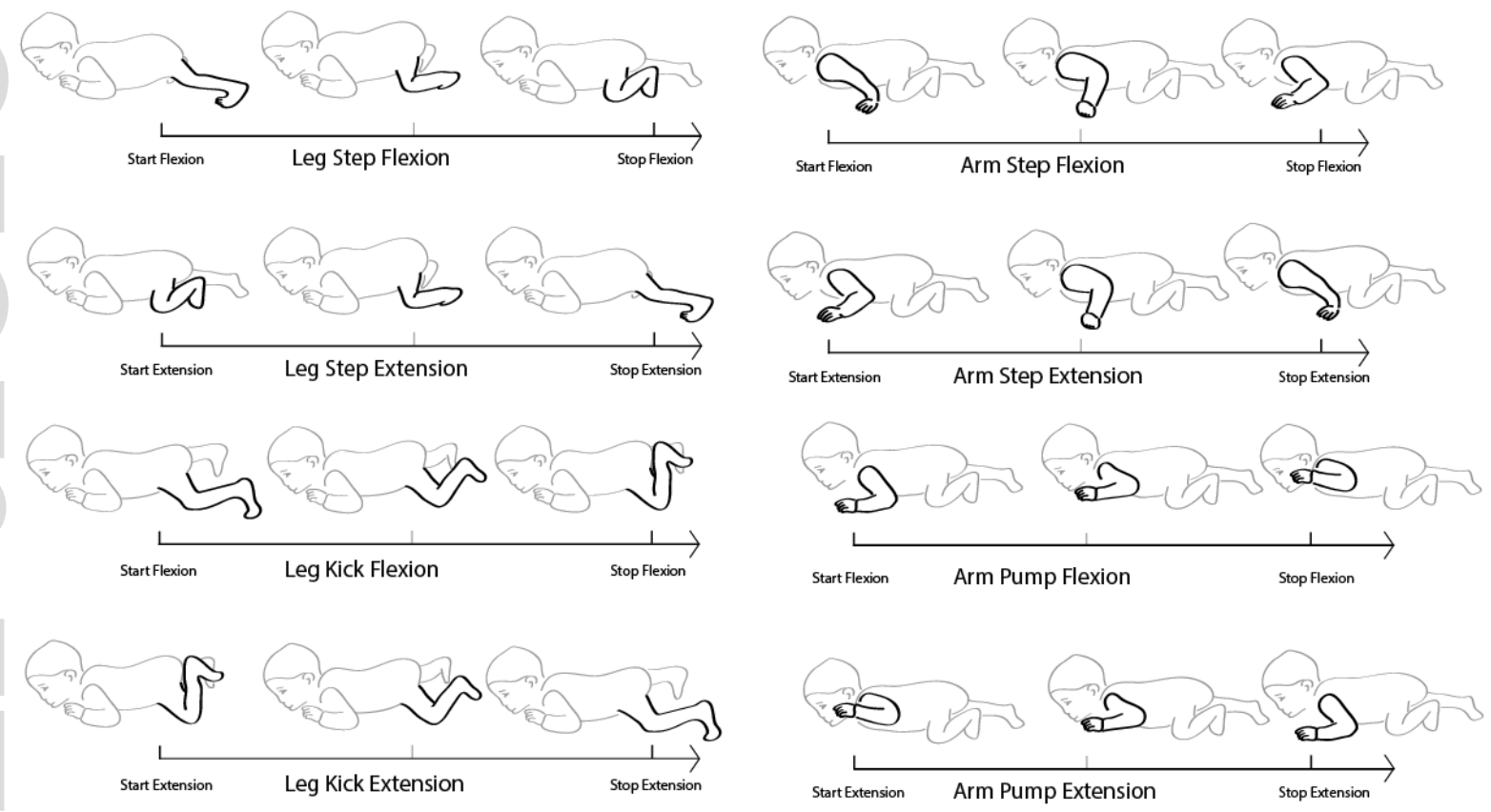

Figure 2 


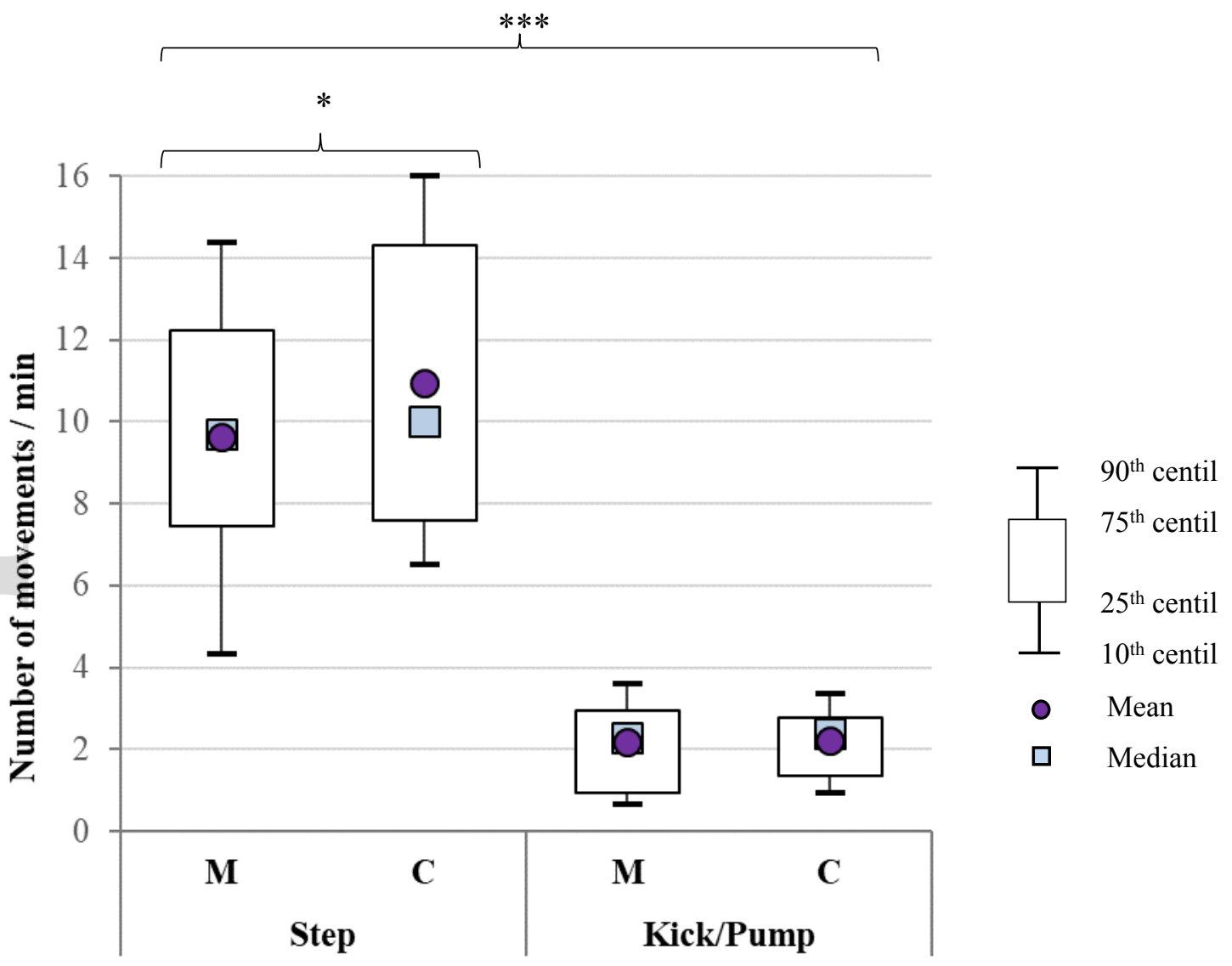

Figure 3

This article is protected by copyright. All rights reserved 


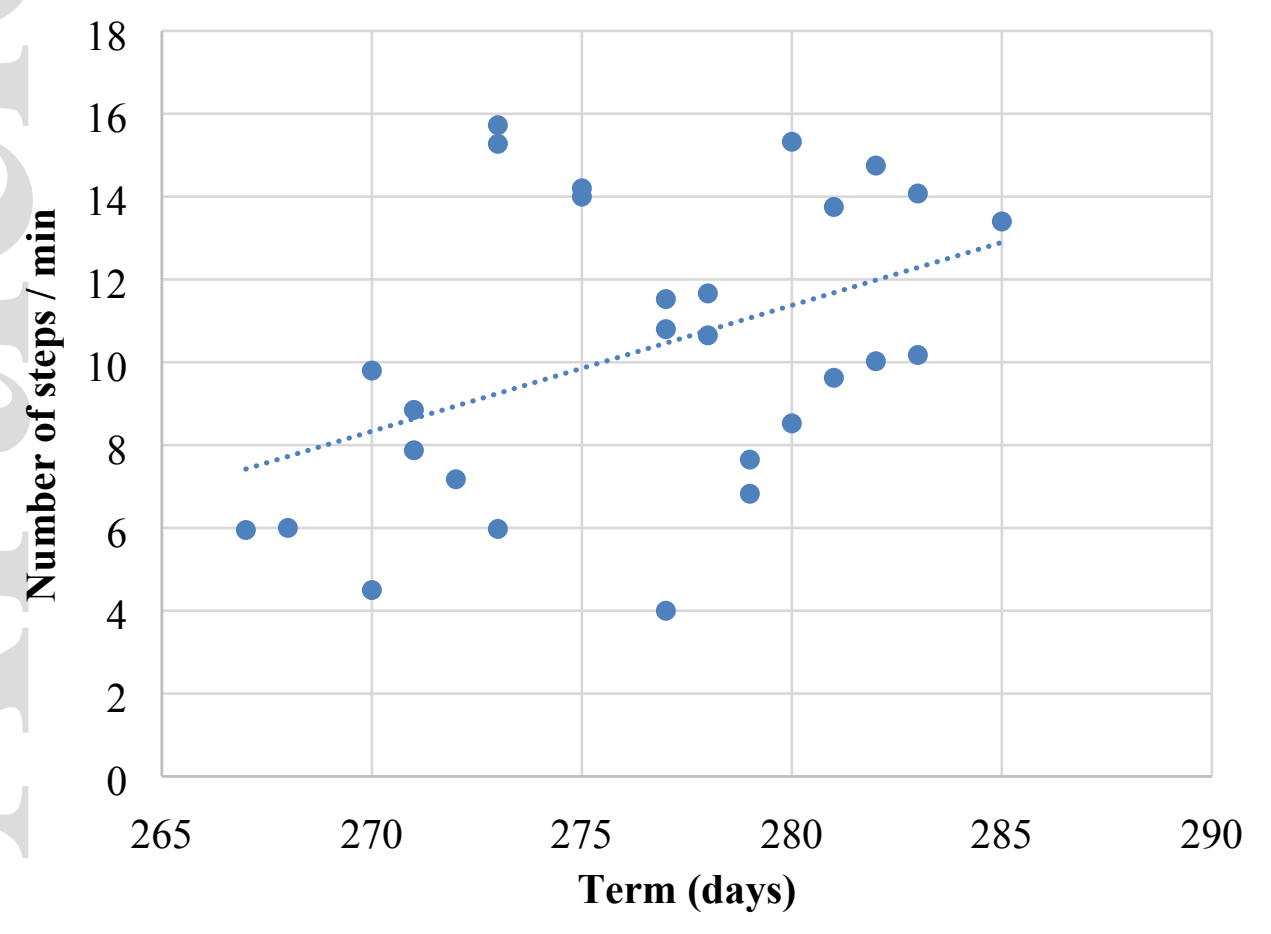

Figure 4

This article is protected by copyright. All rights reserved 